\title{
Teaching Literature for Undergraduate Students at Tribhuvan University, Nepal
}

\author{
Dr. Ramesh Prasad Adhikary* \\ Assistant Professor (English) TU. M. M. Campus, Nepalgunj, Nepal
}

*Corresponding Authors: Dr. Ramesh Prasad Adhikary, Assistant Professor (English) TU. M. M. Campus, Nepalgunj, Nepal

\begin{abstract}
This research paper aims to provide an overview of past practices and current status with regard to the teaching of English literature at the undergraduate level, especially to Literature major students of Tribhuvan University, Nepal. It is argued that there has been very little change in the teaching methods for literature. In Nepal, literature teaching means provide a biographical account of the writer and explicate the texts, even dictating notes to students. As such, students have not been involved in the process of grappling with the texts on their own. The paper establishes the urgent need for re-examining the situation and suggests future directions for the whole exercise to become relevant and meaningful to students as well as teachers in Tribhuvan University.
\end{abstract}

Keywords: ESL/EFL, Teacher-centered, student-centre, English Majors, literary/non-literary

\section{INTRODUCTION}

Language teaching methodology has been greatly changed than the past. The 'developments' in the field of teaching English literature over the past fifty years or so, however, have been few and sporadic. On the one hand, the place of literature in a language curriculum has been debated over and over again, and literature is now accorded a place, albeit grudgingly, in an ESL/EFL classroom. It is now recognized that literature can be used as one of the authentic resources in the language classroom along with non-literary resources like newspapers, magazines, brochures, and so on. Another positive development has been the large number of publications that provide useful classroom techniques for using literature in the ESL/EFL classroom.

Despite these efforts, however, the teaching of English literature at the undergraduate level in Tribhuvan University as the Literature Major has remained essentially the same throughout this long period - teacher-centred and teacher-directed, the literary texts being presented to students through lectures, summaries and paraphrases, with little or no involvement of students in understanding and appreciating those texts on their own.

The aim of this paper is to examine the current practices relating to the teaching of English literature at the undergraduate level of Tribhuvan University and suggest the directions the field should take in future if it were to be meaningful and relevant to students and not continue to be a wasted effort, as it has been till now.

\section{ENGLISH EDUCATION IN NEPAL}

The history of English language teaching in Nepal is about a half a century. The first English language education opened to the people in 1951. Earlier education was limited to the members of the royal family and there were not any public schools across the country. After restoration of social equality in the nation, Tri-Chandra College started teaching English courses under the supervision of Patana University, India in the early fifties.

The first university of the country, Tribhuvan University, was established in 1959 which gave high priority to its curriculum in English. But after a decade, a national wide master plan know as The National Education System Plan (NESP 1971-76) was implemented that brought a drastic change in the system of curriculum, textbook, examination and so on from primary to the university levels of education. First, this plan reduced the weight age of English courses (from 200 marks to 100 marks) 
set up by earlier system. Second, it reduced the credit hours of English from 15 to 10 from high school to university levels (Mall, 1977).

Later in 1981, Tribhuvan University brought a change in the structure of English syllabi allotting weight age of 200 marks instead of 100 to the campus level English. The university also discontinued the semester system and reintroduced the annual system of teaching and assessment (Mall, 1977).

In last three decades, English language teaching has been improved largely in Nepal. The change can be noticed in terms of structure of Education, pedagogies and institutions of higher learning. The school level of education consists of five years of primary, three years of lower secondary, two years of secondary and two years of higher secondary teaching. Likewise, in tertiary level, three to four years of Bachelor's degree, two years of Master's Degree and a research based three to five years terminal doctorate degrees are offered in the colleges and universities in Nepal.

\section{Past Practices and Current Status}

The teaching of English literature to students majoring in English at Tribhuvan University had seen very little change over the past several decades. In many classrooms, the teaching of literature has remained unchanged with emphasis on teacher-centred and text-directed approaches and methods (e.g., lectures; period and genre surveys; biographical summaries; teacher's explication and 'critical analyses' of canonical texts; stereotyped exam questions requiring stereotyped answers). Literary texts continue to be taught as finished products, to be unilaterally decoded, analyzed, and explained (Kramsch p. 356; cited in Harper 1988).

Such an approach tends to minimize learner involvement, engagement and participation, and undermines the value of learners' responses to literature as readers in their own right, resulting in frustration and a lack of interest and motivation on the part of learners. Most of our undergraduate students also have limited analytical skills for responding to literary texts as works of art and for articulating their experiences of reading such texts when asked to do so. For linguistic and criticalthem, the course in English literature may become a "painful lesson in deciphering" (Santoni p. 434; cited in Harper 1988).

While reading literature, "students are expected, as if by osmosis, to acquire a kind of competence in reading literature" (Lazar, 1993). It may, therefore, be safely asserted that "we unfairly blame our students for difficulties that essentially stem from our own methodological weaknesses and unrealistic expectations" (Scher p. 56; cited in Harper 1988).

The situation has also been complicated by confusion over the objective of literature teaching, whether it is increasing the language proficiency of the learners, or transmitting the cultural and social values embodied in them, or developing in the learners an adequate capacity for responding personally to literary texts, and interpreting and appreciating them appropriately.

Teachers and educational policy makers have not made sincere attempts to clarify to themselves what exactly they are seeking to develop in learners except by making vague statements, such as 'sensitizing students to great literature and developing their literary competence'. This is the central problem with literature teaching at the undergraduate level; that is, to specify the particular function of literature in the educational system in terms of specific objectives and, consequently, to spell out in no vague terms what is meant by the notion of 'literary competence' (Ramani 1986). Besides, students' attitudes and goals in terms of linguistic and literary competence are not given importance in curriculum design (Akyel and Yalcin 1990).

The literature syllabus has been hitherto spelt out only in terms of texts and historical periods; the methodology has been confined almost to lectures; and the evaluation of literary learning has only been emphasizing rote memory and reproduction of borrowed critical opinions. In other words, there has been very little reading and study of literature with clearly spelt out objectives and methodology.

The teachers of English at the undergraduate level and above have maintained that applied linguistics cannot make inroads upon literature teaching as such studies are essentially subversive and felt to be a threat to the aesthetic and humanistic dimension of literature. These teachers would maintain that application of linguistic principles or language teaching insights would only amount to 'murdering to dissect' aesthetic artifacts and hence the whole exercise would be demotivating to students. This is 
not a valid assumption, as it only tends to mystify literature and thus make it inaccessible to a majority of students.

A review of published work on teaching literature brings into focus the following major issues identified by researchers, for example Paran (2000):

1. The role of literature within the mainstream of EFL is still not firmly established despite a fairly steady stream of theoretical publications and teaching materials; For a majority of ESL/EFL teachers, literature is still not considered to be an essential element of ESL/EFL students' overall learning experience.

2. ESL/EFL teaching and the part which literature has to play within it have not been seen as part of the whole educational endeavour, but apart from it. For many years, there has been a tension between an instrumental view of literature (i.e., beneficial to language learning) and a humanistic view of the role of literature in the target language within the larger educational system.

3. The methodology to be used and its role have not been outlined clearly. Ways of exploiting a few selected poems, short stories, or novels have been suggested, but principled ways of matching appropriate methodologies to types of text have still not been proposed.

The current situation regarding the English Literature Major programme has been summarized by Mekala (2009). Learners' needs and interests are neither documented nor considered at the time of preparation of English literature syllabuses. The students, a vast majority of whom have low proficiency in English, are exposed to challenging and often unsuitable texts, which are beyond their understanding and linguistic competence. The teacher, therefore, resorts to lecturing, explicating and translating the texts, and dictating notes.

The current practices tend to promote content-based and memory-oriented study of literature. Classroom teaching usually consists of a long monologue by the teacher on a piece of literature, this monologue taking the form of the teacher primarily attempting to explain the meaning of the text preceded by a 'brief' introduction to the author and his works. The teacher may be much admired for his erudition or scholarship, but his lectures are little understood. As a result, students rely almost exclusively on guidebooks and resort to rote learning. The inevitable result of all of these is that the students hardly feel the necessity to have a direct encounter with the texts - they are passive listeners, and are not encouraged to react to what they read, or think critically, or do any original writing on the texts.

Moreover, the teaching and study of literature are largely exam oriented. Examinations also seek to test students' memory of reproducible content. The focus seems to be solely on passing examinations and acquiring a paper qualification. This has a negative wash back effect on teaching. It is interesting to note that, for nearly 25 years, the situation does not seem to have changed -stating clear objectives, principled selection of texts, appropriate methods and strategies of using those texts, and valid methods and tools for assessing students' literary competence (Ramani 1986).

\section{FUTURE Directions}

From the discussion above, it is clear that there has been very little change in how English literature has been taught at the undergraduate level as a major or specialist subject of study over half a century. If the status quo were to remain, the relevance and popularity of the English literature curriculum would decline further considerably and it might continue to exist in universities and colleges, but only in a vegetative state devoid of any life. Several steps have, therefore, to be taken immediately to make literature teaching more meaningful, relevant and purposeful to the learners as well as more satisfying to the teachers.

The 'literature major' curriculum should aim at developing in the learners an adequate capacity for responding personally to literary texts, and interpreting and appreciating them appropriately. This "fundamental ability of a good reader of literature" is "the ability to generalize from the given text to either aspects of literary tradition or personal or social significances outside literature" (Brumfit, 1985:108). The process of reading is a process of meaning-creation by integrating one's own needs, understanding and expectations with a written text (ibid:119). One of the first steps is, therefore, to evolve a theoretical model of what is involved in responding to literary texts, i.e. literary competence. Literary competence is taken to refer to a complex network of procedural capacities with which a 
reader interacts with a literary text on the basis of shared conventions. It is the procedural capacity on the part of the reader to bring into convergence the textual patterning signaled by the writer through cues such as foregrounding and the schematic pattern in his own consciousness and thus establish coherence and meanings (Ramani 1986). In effect, this model of literary competence should incorporate a dynamic view of discourse processing and should be relevant and useful to the reading and interpretation of literary texts.

This literary competence should be spelt out in terms of its constituent or component skills and subskills, similar to the attempts to spell out the dimensions of communicative competence in terms of language skills and sub-skills (Yalden 1983; CEFR 2001). Taxonomy of measurable competencies, proficiency levels and indicators should be evolved. It is worth remembering that "in the area of literary education, the focus on competences and their assessment has to be put in the context of a broader conception of the purposes of education" (Pieper 2006:6).

Another future direction should be to develop clear statements and guidelines on teaching methodology. It has been pointed out that the main orientation in literature study has been contentbased and that too much energy is expended on rote learning and reproduction of isolated facts, thus rendering learning and study unnecessarily laborious. There has to be a shift of emphasis away such from episodic knowledge to conceptual relational knowledge, i.e. from the memorization of facts towards the development of a powerful and flexible set of strategies for acquiring, organizing and applying knowledge irrespective of the specific content in a text.

There is a need to examine what is really involved in the interpretation of literary discourse and consequently to explore appropriate strategies for developing the procedural competence to interpret literature. Literary texts by their very nature allow for divergent responses and hence offer enormous scope for interactive strategies to be developed in the classroom provided suitable tasks are formulated to create the required communicative pressure. Teachers must adopt a variety of teaching methods instead of following the same route and "the students should be encouraged to play a dynamic and creative role in literary study" (Jia and Miao 2009:18).

There should be a corresponding effort towards specifying principles of selection and grading of literary texts on the syllabus, such as proceeding from the familiar to the less familiar. If literary texts are to be used successfully, they must be carefully selected and approached in a manner which promotes an aesthetic interaction between the reader and the text. Obviously, the teacher has to make choices about what is to be read by students, what sort of assistance the students need before and while they are reading, and what type of follow-up exercises to give. "If we are talking about helping students to read, we need to look at what we are talking about in the classroom from the teacher's, not the academic's point of view" (Gower 1986).

It is important to know students' needs and attitudes towards studying literature in an ESL/EFL setting. Students have many fears and anxieties about studying literature, especially poetry. Student attitudes, taken along with teacher goals and suitable texts well chosen, will make the course satisfying to students and teachers alike (Hirvela and Boyle 1988; Ramani and Al-Mekhlafi 2009). The literature syllabus should be an accurate reflection of student needs and classroom activities should be primarily student-centred. The essential factor is to create conditions in which students can develop genuine response to literary texts.

The use of literary works written in non-native varieties of English will make it easier for the teacher to enhance the students' awareness of their own society, their sense of self identity, their communicative competence within their community, and their command of the standard language itself (Talib 1992). The incorporation of multicultural literary texts in the curriculum will "introduce students to an exciting and challenging range of world literature, particularly, postcolonial literatures in English", "help students develop a critical understanding of literary variations", and "give students a substantial introduction to non-canonical texts and the relationship of culture, politics and history to the study of literature." (Mohammadzadeh 2009:27).

Finally, the existing examination format should be thoroughly examined for its effectiveness in achieving the redefined objectives and modified to help assess learners' literary competence. Within the classroom, the teacher needs to devise activities that will assist in the process of developing the skill that might be measured finally in the literary essay. Literature examinations should return 
students to the text and its uses of language as the originating centre of their experiences (Carter and Long 1990).

\section{CONCLUSION}

In conclusion, it may be said the suggestions made here are tentative, but they should be attested through specific proposals and empirical work in varying contexts so that their validity and feasibility are established. English as a second/foreign language is a demanding course of Nepalese academia. English has been taught and spoken in Nepal for past half a decade in schools and colleges along with other several local and regional languages. The problems of ELT have noticed in English syllabi, textbooks, policy matters, classroom environment are major components to change in Nepal. The studies have found that there was a strong need for English in Nepal and the country needed welltrained teachers, improved textbooks, enough supplementary materials, and better evaluation system. English educators in Nepal to have teachers' manual, small class size, audio-visual materials, workshops, in- service training and incentives to the teacher. Advanced program packages with student- cantered teaching methods, materials, trainings and structural design are recommended to improve existing trend of teaching and learning English in Nepal.

\section{REFERENCES}

[1] Akyel, Ayse and Yalcin, Eileen (1990). Literature in the EFL class: a study of goal-achievement incongruence. ELT Journal, 44/3:174-180.

[2] Carter, Ronald and Long, Michael N. (1990). Testing literature in EFL classes: tradition and innovation. ELT Journal, 44/3:215-221.

[3] CEFR (2001). The Common European Framework of Reference for Languages: learning, teaching, assessment. Cambridge: Cambridge University Press.

[4] Gower, Roger (1986). Can Stylistic analysis help the EFL learner to read literature? ELT Journal, 40/2:125-130.

[5] Harper, Sandra M. (1988). Strategies for Teaching Literature at the Undergraduate Level, The Modern Language Journal, 72(4):402-408.

[6] Hirvela, Alan and Boyle, Joseph (1988). Literature courses and student attitudes. ELT Journal, 42/3:179-184.

[7] Jia, Yu-ping and Miao, Yong-gang. (2009). New concept on teaching English literature to college English majors, Sino-US English Teaching, 6(5):15-18.

[8] Lazar, Gillian. (1993). Literature and Language Teaching: a Guide for Teachers and Trainers. Cambridge: Cambridge University Press.

[9] Mohammadzadeh, Behbood. (2009). Incorporating multicultural literature in English language teaching curriculum, Procedia Social and Behavioral Sciences, 1:23-27.

[10] Paran, Amos (2000). Survey review: Recent books on the teaching of literature. ELT Journal, 54/1:75-88.

[11] Pieper, Irene. (2006). The Teaching of Literature. Report presented at the Intergovernmental Conference on languages of Schooling: towards a Framework for Europe. Language Policy Division, Strasbourg, (October 2006).

[12] Talib, Ismail bin Said. (1992). Why not teach non-native English literature? ELT Journal, 46/1:51-55.

[13] Yalden, J. (1983). The Communicative Syllabus: Evolution, Design and Implementation. Oxford: Pergamon.

\section{AUTHOR'S BIOGRAPHY}

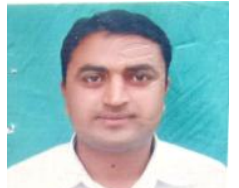

Dr. Ramesh Prasad Adhikary, is an assistant professor of Tribhuwan Univeristy, Kathmandu, Nepal. He has been teaching English literature at M.M. Campus since 2007. He has completed his $\mathrm{PhD}$ in Existential philosophy and has been researching on literary theories. He has created more than 40 international articles and 18 books on various topics of English literature.

Citation: Dr. Ramesh Prasad Adhikary. Teaching Literature for Undergraduate Students at Tribhuvan University, Nepal "International Journal on Studies in English Language and Literature (IJSELL), vol 8, no. 4, 2020, pp. 26-30. doi: http://dx.doi.org/10.20431/2347-3134.0804004.

Copyright: (C) 2020 Authors. This is an open-access article distributed under the terms of the Creative Commons Attribution License, which permits unrestricted use, distribution, and reproduction in any medium, provided the original author and source are credited. 